\title{
EDITORIAL
}

\section{To sleep, perchance to leak}

\author{
D.O. Rodenstein*, P. Levy**
}

Intermittent positive pressure mechanical ventilation (IPPV) can be applied invasively (through a tracheotomy or an endotracheal tube) or noninvasively, using nasal, oral or facial interfaces. Three different types of physician have been involved in treating patients with this kind of therapy: intensive care specialists, pneumologists (also called pulmonologists or respiratory physicians) and sleep physicians. Each group has its own background, points of view and prejudices, which, at least in part, determine the way in which noninvasive mechanical ventilation is implemented.

A stereotypical (though not far from real) intensive care unit patients is a naked human being, lying flat on a relatively sophisticated bed, unaware of the environment. Tubes are inserted into most natural orifices, sometimes more than one tube into a single orifice. Tubes are also inserted through the skin. Some of these tubes are connected to machines and some to bottles, plastic bags or a series of syringes and pump injectors. Sensors are also taped over the chest, or one finger, and around one arm. The bed itself is generally surrounded by monitoring screens displaying numbers and physiological curves, as well as at least one breathing machine and sometimes also an artificial kidney, or a second respiratory machine pumping blood from, and back into, the body of the patient. All this equipment is provided with alarms and beeps; thus, the room is far from silent.

To keep patients alive during the organ(s) failure episode that brought them to intensive care in the first place, all of this paraphernalia is required for hours, days or weeks. To make life bearable, patients are heavily sedated and, sometimes also paralysed. Hours go by, the sun sets, and then rises again as electric lighting makes night the same as day. For the attending intensive care specialist who controls a patient's breathing by means of an external mechanical repirator and endotracheal tube, tidal volume is tidal volume, irrespective of the hour.

Outside intensive care units, human beings may sometimes be ill enough to justify the replacement of a failing organ with an external mechanical device. Examples of such devices are artificial kidneys, or a mechanical heart. Dialysis allows for extended life expectancy, yet it is carried out periodically; the patient is connected to the ar-

*Cliniques Universitaires Saint-Luc, Université catholique de Louvain, Brussels, Belgium. **Dept of Respiratory Medicine and Sleep Laboratory, PRETA Laboratory TIMC UMR CNRS 5525, University Hospital, Grenoble, France.

Correspondence: D.O. Rodenstein, Cliniques Universitaires Saint-Luc, Service de Pneumologie, Av. Hippocrate 10, 1200 Bruxelles, Belgium. Fax: 3227643703

Supported, in part, by grant No. 3.4533.98 from the Belgian Funds National de la Recherche Scientific. tificial kidney machine approximately three times per week for several hours. The rest of the time, the patients can live a quite normal life on their own. To increase free time, some patients are dialysed while they sleep, in order to maximize the time available for the pursuit of personal goals while awake. Respiratory failure is often treated in the following way: patients are connected to an external mechanical device during sleep, thus leaving them free of respiratory assistance during wakefulness. However, contrary to dialysis, free time while awake, is not the only reason for using this adapted method. It is justified by the specific effects of sleep on respiration. Physicians experts in this type of knowledge are generally far removed from intensive care medicine, and pertain, for the most part, to the domain of respiratory and/or sleep medicine. For this type of specialists, tidal volume at 0:00 may be quite different from tidal volume at 12:00 h.

A curious (but trivial) observation is that experts in different aspects of medicine rarely speak to each other. More troublesome is the fact that, when they speak to one another, they rarely understand what the other person means as the discourse goes through the various filters imbedded in the brain. Thus, it comes as no surprise that intensive care and sleep specialists do not communicate. This lack of dialogue is facilitated by the exotic nature of each other's knowledge. For the intensive care specialist, sleep lies outside his field of personal or professional experience. Patients sleep very badly in the intensive care unit, with its noisy environment and permanent artificial lighting, in which nurses and physical therapists frequently perform various controls, irrespective of the time of day or night [1, $2]$. For the traditional sleep specialist, organ failure and support, invasive monitoring, sedation and paralysis, and life and death are remote notions, rarely encountered in their everyday professional experience. In the treatment of patients with respiratory failure, this absence of dialogue may have deleterious health consequences.

Until very recently, the essential difference between mechanical ventilation applied inside or outside the intensive care unit was that patients in intensive care units were intubated and tracheotomised, whereas patients outside intensive care were connected to ventilators through nasal or facial masks (noninvasive (nasal) IPPV (nIPPV)). The latter has now, definitely, found its way into intensive care [3]. The problem is that when patients sleep during nIPPV (whether inside or outside intensive care), they behave in strange ways, that may surprise intensive care (but not sleep) specialists. For instance, they may show large amounts of leaks, whereas no leak is evident when the same patient is ventilated during wakefulness with the same ventilator, the same mask and the same settings. This has serious ventilatory consequences: when leaks are large, 
the patient is left with minimal (if any) ventilatory assistance: most of the air delivered by the ventilator escapes through the leak to the same atmosphere from whence it came into the ventilator; the room is part of the patient's dead space!

Of course, if the patient was in respiratory failure before starting nIPPV, the patient is left in the same state when sleep-related leaks appear. And this, in turn, may lead to other serious consequences: absence of correction or worsening of hypercapnia (hypoxia may be easily corrected by supplemental oxygen, although this is not the best thing to do), with its various cardiovascular implications, and, less easily perceived, sleep impairment [4]. This, probably, derives from a number of factors, from changes in blood gas concentrations to mechanical stimuli arising from the upper airways. When nIPPV is applied during sleep, for 1 night, sleep impairment may not be a serious matter. When it is applied for several nights in a row, or for extended periods of time, sleep disruption becomes an essential matter. Indeed, a whole series of sleep and respiratory control mechanisms are impaired by sleep disruption, including the ventilatory response to hypercapnia or hypoxia, the ventilatory response to added inspiratory loads and, amongst others, the arousal threshold. These can contribute to the persistency or worsening of respiratory failure [5-8]. When patients are sleep-deprived (this means absence of sleep as well as prolonged sleep disruption), wakefulness itself becomes unstable, with episodes of sleep interspersed with a few seconds of wakefulness. In analogy to the short arousals typical of sleep apnoea or periodic leg movement, i.e. microarousals, the short episodes of sleep, interrupting wakefulness, are sometimes termed microsleep [9]. In such a situation, ventilation becomes unstable, waxing and waning as the subject enters microsleep and then recovers full wakefulness. The use of nIPPV can lead to all of these consequences.

The good news is that the gap may be beginning to close. In this issue of the European Respiratory Journal, TESCHLER et al. [10] present very interesting and compelling data. They studied a number of patients on long-term (up to 11 months) home mechanical ventilation that complained of mouth leaks during sleep. They found that ventilatory assistance was very poor during periods of leakage, and also found that sleep was of very poor quality, with excessive sleep disruption by short arousals. When mouth leaks were abolished (with a quite efficient though primitive method: patients were gagged), both sleep and ventilatory improved, and nIPPV became more efficient. TESCHLER et al. [10] found that large leaks could be observed, without obvious opening of the mouth, as air escaped through a corner of the apparently closed mouth. It is unfortunate that the authors do not mention the relationship between leaks and arousals. They provide the information that the arousal index was excessively high during the control night, and was reduced by more than half with mouth closure. It would have been interesting to know whether arousals were due to leaks, i.e. whether they were more prevalent during periods with large leaks than during periods with less or no leaks. Similarly, it would have been interesting to know whether during large leaks effective ventilation (the ventilation effectively reaching the lungs) decreased, or dropped to zero. Since they measured ribcage and abdominal movements, this information was available from their recordings. Gas delivered from the ventilator can follow several routes during nIPPV: 1) it can leak between the skin and the mask; 2) it can leak through the mouth, flowing through the verolingual sphincter, the virtual oral cavity and the lips; 3) it can "leak" into the pharynx, pushing out its compliant walls and remaining there [11]; 4) it can leak into the digestive tract, through the weak superior oesophageal sphincter; and finally, 5) it can flow through the glottis into the respiratory tract, the only useful route. The glottis is an essential structure in nIPPV, since, in response to assisted ventilation with positive pressures, it can substantially narrow and even, completely close, thus increasing the risks of leaks, decreasing the usefulness of nIPPV and impairing sleep quality $[12,13]$. It has been shown that changing the delivered tidal volume, inspiratory flow and ventilatory frequency, or the positive inspiratory pressure (as well as manipulating the ventilatory mode), can influence the glottic response and improve the ventilation effectively reaching the lungs during sleep $[14,15]$. Teschler et al. [10] attributed the decrease in ventilation and the poor sleep quality to the presence of leaks (i.e. once a leak appears, ventilation decreases). Indeed, they include a study in normal subjects and a mathematical model showing that, during voluntary mouth leaks pharyngeal pressure swings decrease, thus lowering the positive pressure available to move gas molecules into the lungs. This is simply natural, but does not prove that ventilation decreases during sleep because of leaks. Were the glottis to narrow during sleep, the glottic route resistance would increase, and for a given inspiratory pressure less air would flow into the larynx and ultimately into the lungs. It has been shown that this increase in glottic resistance can be substantial using both volume-cycled and pressure-cycled ventilators $[12,16]$. Thus, the continuous gas flow, coming from a two-level positive pressure ventilator, would follow the routes of lower resistance, such as the mouth, and mouth leaks (amongst others) would increase following (not preceding and causing) the decrease in ventilation. Once the leak is established, pharyngeal pressure swings would of course decrease. For this to be true, the patients should have stopped breathing spontaneously, i.e. the ventilator set in the spontaneous/ timed $(\mathrm{S} / \mathrm{T})$ mode should behave in the timed mode. Indeed, in the spontaneous mode, the glottic aperture remains normal during nIPPV in sleep [10]. It is, again, unfortunate that TESCHLER et al. [10] did not inform the reader whether the ventilator was triggered by the patients or functioned in the timed mode (both are possible in the $\mathrm{S} / \mathrm{T}$ mode) during periods with large leaks.

It is useful to stress that nocturnal noninvasive ventilation is not a treatment for nocturnal respiratory failure. It is a treatment for permanent respiratory failure that is applied during sleep. It is, indeed, during sleep that respiratory failure is most severe because of the added impact of the sleep-dependent decrease in ventilation upon the already existing respiratory failure in wakefulness. It is interesting to note that TESCHLER et al. [10] did not perform a polysomnographic study under nIPPV before sending the patients home with a respirator. They stated that this was the case because sleepiness was not a symptom at that time. Instead, they relied upon reasonable nocturnal oxygen saturation, transcutaneous carbon dioxide tension traces and improvements in morning blood gas levels. 
What lessons are to be learnt from the work of TESCHLER et al. [10]? Probably the most important one is that pneumologists/intensive care practitioners working with noninvasive intermittent positive pressure ventilation should become aware of all the interactions between sleep and breathing. The second lesson is that home noninvasive intermittent positive pressure ventilation should not be started without polysomnographic control of the effects of noninvasive intermittent positive pressure ventilation on breathing during sleep. This is far from standard practice in most centres, and is exemplified by the lack of pertinent data in the study by Teschler et al. [10]. Interestingly (although perhaps fortuitously) sleep quality during noninvasive intermittent positive pressure ventilation appears much better in centres in which polysomnographic control (and fine tuning of the settings) is the rule before sending a patient home with a respirator [17]. The final lesson is that sleep specialists should be prepared to maintain a fruitful dialogue with intensive care specialists, contributing to their scientific background and answering the many questions that they will ask (this will not be the easiest part), for the benefit of patients on noninvasive assisted ventilation.

\section{References}

1. Shilo L, Dagan Y, Smorjik Y, et al. Patients in the intensive care unit suffer from severe lack of sleep associated with loss of normal melatonin secretion pattern. $\mathrm{Am}$ J Med Sci 1999; 317: 278-281.

2. Freedman NS, Kotzer N, Schwab RJ. Patient perception of sleep quality and etiology of sleep disruption in the intensive care unit. Am J Respir Crit Care Med 1999; 159: 1155-1162.

3. Brochard L, Mancebo J, Wysocki M, et al. Noninvasive ventilation for acute exacerbations of chronic obstructive pulmonary disease. $N$ Engl J Med 1995; 333: 817-822.

4. Delguste P, Aubert Tulkens G, Rodenstein DO. Upper airway obstruction during nasal intermittent positivepressure hyperventilation in sleep. Lancet 1991; 338: 1295-1297.

5. Bowes G. Arousal responses to chemical stimuli during sleep. J Dev Physiol 1984; 6: 207-213.

6. Brooks F, Horner RL, Kimoff RJ, Kozar LF, RenderTeixeira CL, Phillipson EA. Effect of obstructive sleep apnoea versus sleep fragmentation on responses to airway occlusion. Am J Respir Crit Care Med 1997; 155: 16091617.

7. Series F, Roy N, Marc I. Effects of sleep deprivation and sleep fragmentation on upper airway collapsibility in normal subjects. Am J Respir Crit Care Med 1994; 150: 481485 .

8. Chugh DK, Weaver TE, Dinges DF. Neurobehavioral consequences of arousals. Sleep 1996; 19: S198-S201.

9. Harrison Y, Horne JA. Occurrence of "microsleeps" during daytime sleep onset in normal subjects. Electroencephalogr Clin Neurophysiol 1996; 98: 411-416.

10. Teschler H, Stampa J, Ragette R, Konietzko N, BerthonJones M. Effect of mouth leak on effectiveness of nasal bilevel ventilatory assistance and sleep architecture. Eur Respir J 199; 14: 1251-1257.

11. Parreira VF, Delguste P, Jounieaux V, Aubert G, Dury M, Rodenstein DO. Glottic aperture and effective minute ventilation during nasal two-level positive pressure ventilation in spontaneous mode. Am J Respir Crit Care Med 1996; 154: 1857-1863.

12. Jounieaux V, Aubert G, Dury M, Delguste P, Rodenstein DO. Effects of nasal positive-pressure hyperventilation on the glottis in normal sleeping subjects. J Appl Physiol 1995; 79: 186-193.

13. Joinieaux V, Aubert G, Dury M, Delguste P, Rodenstein DO. Effects of nasal positive-pressure hyperventilation on the glottis in normal awake subjects. J Appl Physiol 1995; 79: 176-185.

14. Parreira VF, Jounieaux V, Delguste P, Aubert G, Dury M, Rodenstein DO. Determinants of effective ventilation during nasal intermittent positive pressure ventilation. Eur Respir J 1997; 10: 1975-1982.

15. Parreira VF, Delguste P, Jounieauz V, Aubert G, Dury M, Rodenstein DO. Effectiveness of controlled and spontaneous modes in nasal two-level positive pressure ventilation in awake and asleep normal subjects. Chest 1997; 112: 1267-1277.

16. Parreira VF, Jounieaux V, Aubert G, Dury M, Delguste PE, Rodenstein DO. Nasal two-level positive-pressure ventilation in normal subjects. Effects of the glottis and ventilation. Am J Respir Crit Care Med 1996; 153: 16161623.

17. Collard P, Dury M, Delguste P, Aubert G, Rodenstein DO. Movement arousals and sleep-related disordered breathing in adults. Am J Respir Crit Care Med 1996; 154: 454459. 